\section{Public health series \\ Series editor G Neilsen}

\title{
The repertoire of human efforts to avoid sexually transmissible diseases: past and present. Part 2: Strategies used during or after sex
}

\author{
Basil Donovan
}

Background/objective: Despite the focus by public health programmes on condoms, chastity, or monogamy, people use a much wider variety of strategies to minimise their personal risk of sexually transmissible disease (STD). The objective of this study was to compile a comprehensive list of personal and societal STD avoidance strategies.

Methods: Data from clinical and research observations, computer searches, and historical texts were pooled.

Results: A variety of behaviours during or after sex, other than condoms, were identified that have been perceived to alter STD risk. STD avoidance strategies were often poorly documented and difficult to disentangle from other drives such as aesthetics, sexual variety, and contraception. They also varied in popularity in time and place. Some examples were douching; systemic and topical prophylactic antimicrobials; non-penetrative sexual practices, post-coital urination; and examining sexual partners' genitalia. Interest in some practices has been recently revived-for example, vaginal microbicides and post-exposure chemoprophylaxis, while others-for example, withdrawal and non-penetrative sexual practices, receive scant attention but may be much more widely used.

Conclusion: The full spectrum of STD avoidance strategies warrants further study because some are ubiquitous across cultures and because they have the potential to complement or undermine safer sex programmes. Because of their greater acceptability, some less efficacious strategies may have greater public health importance than less popular but more efficacious strategies such as condoms.

(Sex Transm Inf 2000;76:88-93)

Keywords: sexually transmitted diseases; HIV; prostitution; military

\section{Introduction}

The accompanying article ${ }^{1}$ outlined the range of strategies that people use, or have used, to reduce their risk of sexually transmissible disease (STD) before (or instead of) engaging in sex. In that article societal responses to STDs and factors influencing sexual partner selection were also discussed.

In this article, the STD avoidance strategies that people initiate at the time they have sex or shortly thereafter are listed. Military and sex industry responses to STDs are also outlined. The methods used to derive this information were described previously. ${ }^{1}$

\section{Strategies adopted during sex}

The male condom received pre-eminence in HIV/AIDS safer sex campaigns ${ }^{2}{ }^{3}$ because it was the most established product, it was biologically plausible, and because it was deemed to be the most acceptable option for the highest risk populations such as homosexually active men and sex workers and their clients. In retrospect, this took considerable courage as it has taken a long time to establish the substantial protective efficacy against HIV transmission of condoms. ${ }^{4}$ The protection provided by condoms against other STDs is more variable. $^{5}$

Globally, however, consistent male condom use remains a minority strategy because of moral objections, limited consumer acceptability, or logistic reasons. The costs of condom use-including financial, interpersonal, aesthetic, and social costs ${ }^{3}$ - are too high for most people. Instead, many people in different settings adapt their sexual practices in ways that do not include male condoms (table 1), often with unknown or only marginal benefit for STD prevention.

Vaginal microbicides are currently the subject of renewed interest because they minimise the need for male cooperation in HIV prophylaxis. ${ }^{6} \mathrm{~A}$ wide range of new compounds and delivery systems is being investigated, with a likelihood that a combination product will emerge with maximum antimicrobial effect and minimum side effects. ${ }^{78}$

\section{Strategies adopted after sex}

Post-coital genital washing, urinating, and applying topical antiseptics (table 2) are all strategies that were more common before better quality condoms and modern antibiotics became available, though they were of dubious value for reasons of poor compliance. ${ }^{9}$ By the 1970 s, before high risk people were willing to accept condoms on any scale, systemic antibiotic prophylaxis was thought to provide the most promise for STD prevention despite its inherent problems. ${ }^{9}$ Globally, doctor initiated post-exposure prophylaxis against STDs remains uncommon. It is much more common for people to self medicate as prophylaxis against STDs. 
Post-exposure systemic prophylaxis against HIV infection (and its potential to undermine safer sex campaigns) has rekindled the concept. ${ }^{10}{ }^{11}$ If affordable, few clinicians would deny access to antiretrovirals for people who had been raped and perhaps people who had experienced a condom failure in an HIV discordant relationship. The debate centres on who else should be provided with antiviral drugs and the need for research assessing their efficacy.

\section{Military responses}

Driven by the imperative to maintain the health of fighting forces that were dislocated from

Table 1 Actions that individuals may take at the time of sex to alter the risk of STDs

Action Comment

Inspect prospective sexual partners' genitals

Commercial sex workers may routinely inspect their clients for discharges and lesions, and sometimes vice versa. ${ }^{28} 34$ This may even include underwear inspection (clinical observation) and abdominal palpation..$^{20}$ Male clients of sex workers may urinate just before inspection to deliberately conceal a urethral discharge. ${ }^{34}$

Avoid sex during menses

Wash partners' genitals just before coitus

Apply antiseptics to the external genitals just before coitus

Bandage or otherwise isolate active herpes lesions Practise oral sex

Practise "non-penetrative" or "esoteric" sex

Practise withdrawal (coitus interruptus)

Avoid saliva as a sexual lubricant

Minimise anogenital trauma during sex

Avoid female arousal (be quick)

Use male condoms

Practise unprotected insertive but not receptive anal intercourse, or "negotiated safety" according to HIV status

Use female condoms

Use vaginal microbicides

Use a female diaphragm

Avoid certain sexual positions

Avoid anal intercourse
Avoiding menstrual blood is a plausible risk reduction strategy for HIV, but there are few data to support it. ${ }^{35}$ Contact with menses has long caused STD fear in men ${ }^{15}$ (clinical observation).

Where water is available, commercial sex workers like to wash clients: perhaps for aesthetic reasons but antiseptics are sometimes used ${ }^{34}$ (clinical observation).

Some very dubious products are on the market (fig 1) which could provide dangerous reassurance. Previously, more plausible preparations such as calomel ("Metchinoff's") ointment were applied to the penis before $\operatorname{sex}^{19}{ }^{36}$ but were abandoned because they caused vaginal irritation or because of moral controversy. Concoctions such as borated vaseline (table 3) were thought to provide a threefold benefit: lubrication minimising trauma, antisepsis, and a physical barrier to the venereal "poison". Fortunately, condoms were probably thick enough in those days to survive the ravages of vaseline. Antiseptics after coitus (table 2) is possibly more common.

This is most practical for extragenital lesions. ${ }^{37}$

Long seen as wanton, various oral sex scenarios include being the insertive or receptive partner in fellatio, cunnilingus, or anal rimming. Oral sex is probably relatively safe for HIV but exposure to semen, blood, or open lesions should be avoided. ${ }^{38}$ Oral sex is riskier for gonorrhoea, HSV infections, and hepatitis A. Condoms or dental dams are often used by commercial sex workers for oral sex. While much discussed, dental dams are rarely used in non-commercial sex (clinical observation).

Esoteric practices include mutual masturbation (perhaps involving vibrators and dildos), "bondage and discipline," fetishes, voyeurism, frottage (genital-body rubbing), intracrural or intracleavage sex, fisting, enema, ${ }^{39}$ and phone sex. The options seem unlimited. ${ }^{40}$ These practices are generally safe, but exposure of blood or anogenital secretions to open lesions should be avoided. ${ }^{41}{ }^{42}$ Gloves can be used for fisting and condoms can be used for masturbation or on a shared dildo. Sterilising a blood contaminated leather whip is a challenge.

Withdrawal is a spectrum of behaviours ranging from penile-vaginal or penile-anal approximation with little penetration, through brief penetration, to penetration with thrusting until just before ejaculation. Unprotected withdrawal may be followed by the use of condoms for ejaculation only ${ }^{43}$ or combined with condoms used throughout intercourse. ${ }^{44}$ Withdrawal is most commonly used as a contraceptive method $^{45}$ but also used against STDs ${ }^{28}$ and against HIV with variable success. ${ }^{27}{ }^{46}$ Withdrawal is popular because it requires no premeditation, ${ }^{47}$ and it is plausible to the lay person and freely available. ${ }^{45}$

Saliva as a lubricant is avoided by Zimbabwean women because its association with spitting positions it as intrinsically "dirty" ${ }^{26}$ Since AIDS, many have substituted commercial lubricants if using condoms because of theoretical concerns about HIV in saliva. ${ }^{48}$

Thrusting during vaginal or anal intercourse can induce trauma that causes bleeding or microtrauma that provides a portal of entry for pathogens. ${ }^{49-51}$ Trauma is more likely in the event of non-consensual sex, defloration, infibulation, vaginal tighteners, atrophic vaginitis, and hurried ("rough") sex. Care not to use excessive vaginal drying/tightening agents is used to reduce trauma. ${ }^{26}$ Publications for homosexual men $^{252}$ recommend ample lubrication, an unhurried approach, and anal relaxation manoeuvres. Foreplay increases lubrication for vaginal sex and relaxes muscles.

Not allowing the woman time to become aroused was thought to minimise exposure to the venereal "venom". ${ }^{53}$ This attitude persists in some men (clinical observation).

The use of male condoms is the focus of HIV prevention in many (but not all) countries. ${ }^{54}$ Condom acceptability is limited by the dependence on male cooperation and logistic issues. ${ }^{3}$ Male condoms have long been perceived as intruding into relationships. ${ }^{55-57}$ Nevertheless, male condoms have achieved acceptance in many of the highest risk situations such as commercial sex, ${ }^{22} 232658$ male to male sex, ${ }^{3344}$ and casual heterosexual encounters ${ }^{25} 59$ often with dramatic effect on STD/HIV incidence at a population level. But achieving such success requires well resourced and broad based programmes. ${ }^{60}$

Conscious of studies indicating reduced transmission efficiency of HIV to the insertive partner, ${ }^{49}{ }^{61}$ but

keen to engage in unprotected anal sex, some homosexual men will practise unprotected insertive but not receptive anal sex with HIV positive or unknown HIV status partners. Conversely, some HIV positive men see it as an acceptable risk for partners to have unprotected insertive but not receptive anal intercourse with them (clinical observation). A refinement of this is "negotiated safety" where both partners determine their HIV status and develop their sexual repertoire together according to their HIV serocordance or otherwise. ${ }^{33} 44$ "Negotiated safety" hinges on retesting, say 3 months into a relationship, before abandoning condoms, plus strict adherence to safer sex guidelines outside the relationship.

This is a new female dependant polyurethrane product that is in its early marketing phase. ${ }^{62}$ The acceptability of the female condom is proving to be variable. Gay men are occasionally experimenting with the product for anal sex (clinical observation).

Several compounds long used as spermicides also have antimicrobial properties: some are being reassessed-eg, cholic acid, ${ }^{63}$ gramicidin, ${ }^{64}$ nonoxynol- $9,{ }^{58}$ gossypol. ${ }^{64}$ Purpose designed vaginal microbicides used in the past have included secret ingredients, ${ }^{57} \mathrm{calomel} / \mathrm{chinosol}$ pessaries ${ }^{56}$ orthoiodobenzoic acid with trethanolamine, ${ }^{65}$ and foaming penicillin tablets ${ }^{66}$

Diaphragms provided unexpectedly high benefit in one cross sectional study ${ }^{67}$ but there are no randomised trial data. The concurrent use of spermicides may have been a significant factor. Diaphragms are occasionally used as a "second line" preventive strategy by sex workers in case of condom failure (clinical observation).

Myths abound, including anecdotes that allowing a woman to get "on top" promotes STD transmission through gravity (clinical observation).

Anal intercourse has most often been used as a contraceptive or pleasure enhancing measure but may have sometimes been considered a protection against STD in the past. ${ }^{68}$ Avoiding anal intercourse is recommended as a major strategy for homosexual men. Because of the greater HIV transmission efficiency of anal over vaginal intercourse, avoiding anal intercourse has sometimes been zealously promoted as an HIV preventive strategy for heterosexuals, ${ }^{69}$ some of whom avoid anal sex as their sole strategy to avoid HIV (clinical observation). 


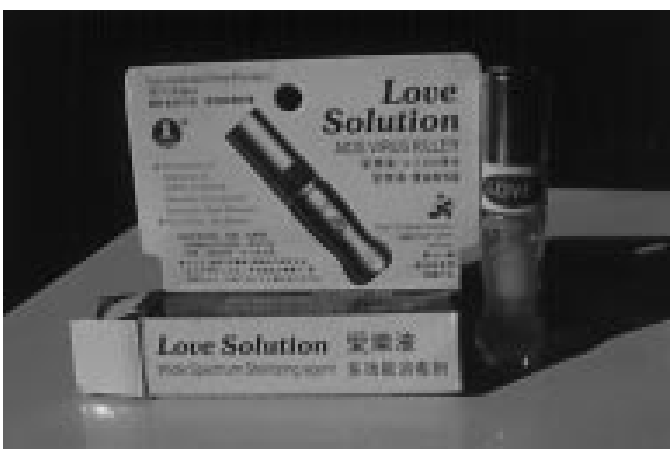

Figure 1 "Love solution: AIDS virus killer" purchased in the foyer of an international hotel in China in 1990. For spraying on the external genitalia before sex. Listed ingredients include "Germicide No 1."

domestic restraints, and aided by diminished public scrutiny, the military has tended to take many of the boldest steps in STD prevention. These steps have included:

(a) graphic education programmes with an emphasis on sexual abstinence and temperance ${ }^{1213}$

(b) variously declaring venues that provide sexual opportunity out of bounds or attempting to regulate local sex industries $^{121415}$

(c) providing (sometimes compulsory) postcoital chemical prophylaxis stations, self administered chemical prophylaxis kits, or condoms ${ }^{13} 16$

(d) punishing soldiers who contracted STD,${ }^{13} 16$ often detected by compulsory medical examinations ("dangle parades")

(e) quarantining infected military $\mathrm{men}^{16}{ }^{17}$ or prostitutes $^{12}$

(f) promoting visits to camp by wives and girlfriends ${ }^{16}$ (g) providing alternative physical and recreational outlets. ${ }^{13} 16$

While the merits of many of these military measures remained unproved, public awareness of STD prophylaxis tended to open up during and after the world wars. Fear of exposing troops to "old world degeneracy" 16 was a significant factor in the US isolationism in the early parts of the world wars. But the military in active service often had high STD incidences to cope with, compounded by the fact that many soldiers deliberately exposed themselves to STDs to avoid serving at the front. ${ }^{17-19}$ The explicitness of the military response (table 3) has only been matched by some of the community based education programmes developed since the AIDS pandemic.

\section{Commercial sex industry responses}

Long perceived by the public and authorities as central to STD epidemiology, ${ }^{20}{ }^{21}$ the sex industry has often responded remarkably to the fear of HIV infection by increasingly using condoms. ${ }^{22}{ }^{23}$ Anecdotally, the demand for conventional (vaginal) commercial sexual services diminished, if only transiently, in many parts of the world with the emergence of AIDS. In response, and facilitated in some cases by technological developments, safer forms of commercial sex have blossomed (table 4). Too little is known about them to determine how much these practices are intended to avoid infection or to cater to an increasing market for sexual variety.

\section{Discussion}

Many potential STD avoidance strategies have been listed here and previously, ${ }^{1}$ though insufficient data are available to determine their

Table 2 Actions that individuals use after sex to alter the risk of STDs

Action Comment

Douching is a second rate contraceptive method that is also used for aesthetic and STD preventive reasons, with or without additional chemicals. ${ }^{70}$ A very common practice, douching possibly increases the risk of pelvic infections and ectopic pregnancy ${ }^{71}$ It is often ambiguous as to what constitutes "douching,"-ie, washing out using a device that provides hydrostatic pressure or simply diligent washing of the lower vagina with the fingers (clinical observation). In the Philippines, some private doctors provide a douching service. $^{28}$

Wash the external genitalia

Pass urine

Apply topical and intravaginal antimicrobial

Irrigate the male urethra

Drink huge quantities of beer

Take post-exposure systemic antimicrobials

Get vaccinated against hepatitis

Get tested for STDs

Washing is frequently performed by sex workers on themselves ${ }^{72}{ }^{73}$ and their clients (clinical observation). One study suggested a protective effect against HIV infection for sex workers if soap and water was used but not water alone. ${ }^{72}$ Washing the genitalia with soap and water was a component of post-exposure prophylaxis regimens used by the military ${ }^{16}$ (table 3 ). Showering is a more subtle alternative. ${ }^{55}$

Urinating immediately after sex is sometimes recommended to women to avert recurrent urinary tract infections and to (particularly military) men to avert urethral infections, but it was never proved to be of benefit for the latter. ${ }^{16} 74$ It is still common practice for some groups of men (clinical observation)..$^{28}$

Prophylaxis was provided; in the form of portable "blue light kits" or "pro-kits," or calomel and carbolic acid ointments at "prophylaxis stations"; to military men and in ports well into this century. ${ }^{16}{ }^{36}{ }^{75-77}$ Post-coital antisepsis is often practised by sex workers but without any evidence of benefit. Products used include mustard oil,${ }^{73}$ lemon and alcohol,${ }^{28}$ toothpaste,${ }^{28}$ soap ${ }^{34}{ }^{72}$ disinfectants,${ }^{34}$ deodorants,${ }^{34}$ and mouthwash. ${ }^{34}$ Some commercial sex worker organisations recommend the use of spermicide only in the event of condom failure.

Chemical (usually dilute potassium permanganate) post-coital irrigation services were provided to soldiers ${ }^{16} 17$ and in ports ${ }^{75}$ around the world well into this century. Often used in combination with topical antiseptics such as calomel, its value was never formally proved.

A folk variant of the former strategy. ${ }^{15}$

Post-exposure antibiotics are a frequently used informal strategy, ${ }^{28} 78$ and more formally applied after sexual assault. Antibiotics were of proved benefit for gonorrhoea ${ }^{77}$ but discouraged for routine use because of the potential for the development of antibiotic resistance and the lack of a single agent to cover all important STD pathogens. ${ }^{9}{ }^{79}$ This issue recently increased in profile because of the potential for direct chemoprophylaxis against HIV..$^{11}$

Hepatitis B vaccination (active and/or passive) is sometimes provided after sexual assault and some other high risk sexual exposures. Hepatitis A vaccination is appropriate after confirmed sexual exposure.

Getting tested is a form of tertiary prevention intended to avert complications of STD if already infected and also to protect future sexual partners. This strategy is limited by test "window periods," test insensitivity, and lack of protection against new infections but it enjoys widespread approval ${ }^{22} 235280-83$ 
Table 3 Instructions * posted by Austrian military authorities in brothels in occupied territories during the first world war

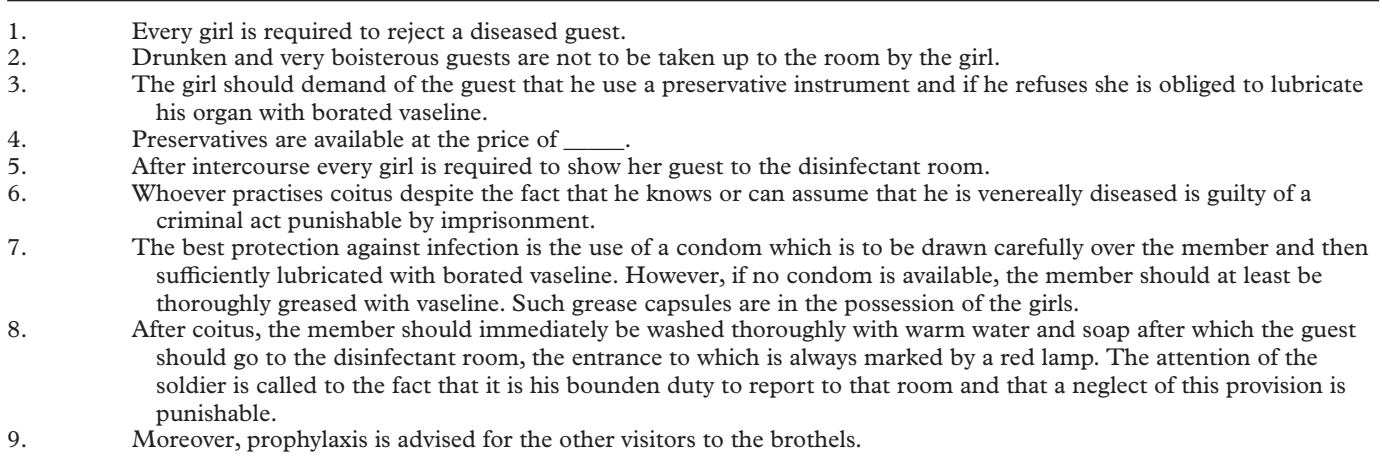

^In three languages—-German, Hungarian, and Croatian. Source: Hirschfeld. ${ }^{84}$

Table 4 Forms of commercial sex that have thrived since the advent of $A I D S$

(1) Consistently protected vaginal or anal intercourse.

(2) Pornography, especially videos and electronic forms.

(3) Telephone sex.

(4) Bondage and discipline, and other fetish services.

(5) Massage with "hand relief" (client masturbated by sex worker).

(6) BJ ("blow job" or fellatio) services.

(7) Lap dancing (intimate stripping without genital contact).

(8) Sexually explicit computer bulletin boards ${ }^{85}$

(9) Virtual sex

*Under development

relative efficacy, prevalence (which varies widely between cultures), or how the people engaging in these behaviours construct and combine them. Some practices that were once common-for example, topical antiseptics for men, are now rare while other practices with a long but low profile history - for example, vaginal microbicides, are currently the subject of considerable interest. ${ }^{78}$

Others, such as partner selection or withdrawal, that may dwarf higher profile strategies in terms of prevalence are not readily amenable to study because they signify a range of behaviours rather than a simple dichotomy. A further barrier to determining the efficacy of alternative strategies through randomised trials is that many of the techniques are readily available and blinding is usually impossible. Ethical concerns also emerge if a strategy of proved high efficacy, such as the use of male condoms, is displaced. ${ }^{24}$ The acceptability of a strategy may also hinge on cultural norms which are subject to change. ${ }^{25}{ }^{26}$ Nevertheless, a practice which may provide only limited STD protection, say $20-30 \%$, but is used by $80 \%$ of the population may have substantially more public health impact than a strategy which has over $90 \%$ efficacy but is only acceptable to $10 \%$ of the population. Programme managers need to be mindful of the heterogeneity of STD avoidance strategies within their local population and perhaps adapt accordingly. A clinician faced with an HIV discordant couple who flatly refuse to use condoms, ${ }^{27}$ despite repeated counselling, may need to discuss withdrawal and/or diaphragm use, to promptly manage any inflammatory genital conditions, and to ensure that the HIV positive partner has the lowest viral load that is achievable.

The effects of informal STD avoidance strategies can be wide ranging. In the Philippines, up to $89 \%$ of commercial sex workers self medicate with antibiotics. ${ }^{28}$ While this is associated with some of the highest rates of drug resistant $N$ gonorrhoeae in the world, syphilis and chancroid are relatively uncommon in this setting. ${ }^{28}$ But irregular use of broad spectrum antibiotics may also increase the prevalence of vaginitis and reduce the efficacy of oral contraceptives.

There seems to be an ongoing and profound resistance by many doctors to discuss sexuality and sexual safety with their patients..$^{29} 30$ Discussion of sexual matters, particularly with women, may be socially precluded. ${ }^{31}$ Eliciting many of the subtle attitudinal, behavioural, and cultural factors listed here requires specialist skills that are not widely available. ${ }^{32}$ Even when risk histories are adequately established, dilemmas arise for clinicians and health educators. For example, practices such as the use of vaginal drying agents ${ }^{26}$ or "negotiated safety" 33 may pose some risk of HIV transmission within a relationship but, by adding quality to that relationship, they may reduce extramural HIV risk. Personal STD avoidance strategies will remain a complex and dynamic area of study, but it is a fascinating and worthwhile field.

Thanks to Virginia Wynne-Markham for preparation of the manuscript and assistance with searches. Thanks also to Graham Neilsen for his helpful comments on the manuscript.

1 Donovan B. The repertoire of human efforts to avoid sexually transmissible diseases: Past and present. Part 1: Strategies used before or instead of sex. Sex Transm Inf $2000 ; 76: 7-12$.

2 West Australian AIDS Council. Condoms: a user's guide. Perth, WA: AIDS Council, 1994.

Donovan B. Condoms and the prevention of sexually transmissible diseases. Br F Hosp Med 1995;54:575-8.

4 Pinkerton SD, Abramson PR. Effectiveness of condoms in preventing HIV transmission. Soc Sci Med 1997;44:130312.

5 Donovan B. Barriers to conception and disease. Ann Acad Med Singapore 1995;24:608-14.

6 Heisse LL, Elias C. Transforming AIDS prevention to meet women's needs: a focus on developing countries. Soc Sci Med 1995;40:931-43.

7 Pauwels R, De Clereq E. Development of vaginal microbicides for the prevention of heterosexual transmission of HIV. I Acquir Immune Defic Syndr Hum Retrovirol 1996;11: 211-21.

8 Larkin M. Easing the way to safer sex. Lancet 1998;351:964

9 Darrow WW, Wiesner PJ. Personal prophylaxis for venereal disease. FAMA 1975;233:444-6.

10 Katz MH, Gerberding JL. Post-exposure treatment of people exposed to the human immunodeficiency virus through sexual contact or injection-drug use. $N$ Engl $7 \mathrm{Med}$ 1997;336:1097-100.

11 Centers for Disease Control and Prevention. Management of possible sexual, injecting drug use, or other nonoccupational exposure to HIV, including considerations occupational exposure to HIV, including considerations
related to antiretroviral therapy. $M M W R$ 1998;47(RR-17): related to 14 .

12 Brandt AM. No magic bullet. A social history of venereal disease in the United States since 1880. New York: Oxford University Press, 1987:52-99. 
13 Lewis M. Thorns on the rose: the history of sexually transmitted diseases in Australia in international perspective. Canberra: Australian Government Publishing Service, 1998:157-9.

14 Fabricius J. Syphilis in Shakespeare's England. London: Jessica Kingsley Publishers, 1994:61-2.

15 Davenport-Hines R. Sex, death and punishment. Attitudes to sex and sexuality in Britain since the Renaissance. London: Collins, 1990:263-6.

16 Brandt AM. No magic bullet. A social history of venereal disease in the United States since 1880. New York: Oxford University Press, 1987:101-18.

17 Tolerton J. Ettie: a life of Ettie Rout. Auckland: Penguin, 1992:195-7.

18 Hirschfeld M. The sexual history of the world war. New York: Cadillac Publishing, 1946:87-8.

19 Tolerton J. Ettie: a life of Ettie Rout. Auckland: Penguin, 1992:152-4.

20 Cohen MS, Henderson GE, Aiello P, et al. Successful eradication of sexually transmitted diseases in the People's Republic of China: implications for the 21 st century. $f$ Infect Dis 1996;174(Suppl 2):S223-9.

21 Lewis M. Thorns on the rose: the history of sexually transmitted diseases in Australia in international perspective. Canberra: Australian Government Publishing Service, 1998:105-21.

22 Laga M, Alary M, Nzila N, et al Condom promotion, sexually transmitted disease treatment, and declining incidence of HIV-1 infection in female Zairian sex workers. Lancet of HIV-1 infection

23 O'Connor CC, Berry G, Rohrsheim R, et al. Sexual health and condom use among local and international sex workers in Sydney. Genitourin Med 1996;72:47-51.

24 Farr G, Castro LAA, Disantostefano R, et al. Use of spermicide and impact of prophylactic condom use among sex workers in Santa Fe de Bogota, Colombia. Sex Transm Di 1996;23:206-12.

25 Rodden P, Crawford J, Kippax S, et al. Sexual practices and understandings of safe sex: assessing change among 18- to 19-year-old Australian tertiary students, 1988 to 1994 Aust NZ F Public Health 1996;20:643-9.

26 Civic D, Wilson D. Dry sex in Zimbabwe and implications for condom use. Soc Sci Med 1996;42:91-8.

27 De Vincenzi I, for the European Study Group on Heterosexual Transmission of HIV. A longitudinal study of human immunodeficiency virus transmission by heterohuman immunodeficiency virus transmission

28 Gacad E, Aquino C, Tempongko S, et al. Philippines (country chapter). In: Brown T, Chan R, Mugrditchian D, Mulhall B, Plummer D, Sarda R, Sittitrai W, eds. Sexually transmitted diseases in Asia and the Pacific. Armidale (Australia) Venereology Publishing, 1998:257-9.

29 Temple-Smith M, Hammond J, Pyett P, et al. Barriers to sexual history taking in general practice. Aust Fam Physician 1996;25(Supp1 2):S71-4.

30 Giffin K, Lowndes CM. Gender, sexuality, and the prevention of sexually transmissible diseases: a Brazilian study of clinical practice. Soc Sci Med 1999;48:283-92.

31 Leng HB. Cambodia (country chapter). In: Brown T, Chan R, Mugrditchian D, Mulhall B, Plummer D, Sarda R, SittiR, Mugrditchian D, Mulhall B, Plummer D, Sarda R, Sittitrai W, eds. Sexually transmitted diseases in Asia and the
Pacific. Armidale (Australia): Venereology Publishing, Pacific. Armid.

32 Epstein RM, Morse DS, Frankel RM, et al. Awkward moments in patient-physician communications about HIV risk. Ann Intern Med 1998;128:435-42.

33 Kippax SC, Noble J, Prestage G, et al. Sexual negotiations in the AIDS era: negotiated safety revisited. AIDS $1997 ; 11$ 191-7.

34 Donovan B. Medico-social aspects of a house of prostitution. Med F Aust 1984;140:272-5.

35 European Study Group on Heterosexual Transmission of HIV. Comparison of female to male and male to female transmission of HIV in 563 stable couples. BMF 1992;304: transmis $809-13$.

36 Tolerton J. Ettie: a life of Ettie Rout. Auckland: Penguin, 1992:124-5.

37 Sacks SL. The truth about herpes. West Vancouver: Gordon Soules Book Publishers, 1997:106-7.

38 Rothenberg RB, Scarlett M, del Rio C, et al. Oral transmission of HIV. AIDS 1998;12:2095-105.

39 Agnew J. Some anatomical and physiological aspects of anal sexual practices. F Homosexuality 1985;12:75-96.

40 Love B. The encyclopedia of unusual sex practices. London: Abacus, 1995.

41 Knobel GJ. An urgent warning-contraction of HIV infection during mutual masturbation (letter). S Afr Med $尹$ 1988;73:617.

42 Donovan B, Tindall B, Cooper DA. Brachioproctic eroticism and transmission of the AIDS retrovirus. Genitourin Med 1986;62:390-2.

43 Richters J, Donovan B. Barrier methods: contraception and STD prophylaxis. Aust Fam Phys 1988;17:874-7.

44 Tindall B, Swanson C, Donovan B, et al. Sexual practices and condom usage in a cohort of homosexual men in relation to human immunodeficiency virus status. Med $\mathcal{f}$ Aust 1989;151:318-22.

45 Richters J. Contraception? No, but we're careful. Healthright 1984;4:30-4.

46 Hecht F, Grant PX, Petropoulos C, et al. Sexual transmission of an HIV-1 variant resistant to multiple reversesion of an HIV-1 variant resistant to multiple reverse-
transcriptase and protease inhibitors. $N$ Engl $f \mathrm{Med}$ transcriptase and

47 Rogow D, Horowitz. Withdrawal: a review of the literature and an agenda for research. Studies in Family Planning 1995;26:140-53.
48 Richters J, Gerofi J, Donovan B. Why do condoms break or slip off in use? An exploratory study. Int $\mathcal{F}$ STD AIDS 1995 6:11-8.

49 Kingsley LA, Rinaldo CR, Lyter DW, et al. Sexual transmission efficiency of hepatitis $B$ virus and human immunodeficiency virus among homosexual men. $f A M A$ 1990;264 230-4

50 Renzullo PO, McNeil JG, Levin LI, et al. Risk factors for prevalent HIV infection in active duty army men who initially report no identified risk: a case-control study. $\mathcal{F}$ Acquir Immune Defic Syndr 1990;3:266-71.

51 Figueroa JP, Brathwaite AR, Morris J, et al. Rising HIV-1 prevalence in STD clinic attenders in Jamaica; traumatic prevalence in $\mathrm{STD}$ clinic attenders in Jamaica; traumatic Immune Defic Syndr Hum Retrovirol 1995;8:215.

52 Donohoe S. Out there! A sexual health guide for young gay men. Sydney: Australasian College of Sexual Health Physicians and Australian Federation of AIDS Organisations, 1997.

53 Davenport-Hines R. Sex, death and punishment. Attitudes to sex and sexuality in Britain since the Renaissance. London: Collins, 1990:46-8.

54 Kamenga M, Ryder RW, Jingu M, et al. Evidence of marked sexual behaviour change associated with low HIV-1 seroconversion in 149 married couples with discordant HIV-1 serostatus: experience at an HIV counselling center in Zaire. AIDS 1991;5:61-7.

55 Chapman S, Hodgson J. Showers in raincoats: attitudinal barriers to condom use in high-risk heterosexuals. Comm barriers to condom use in higt
Health Stud 1988;12:97-105.

56 Tolerton J. Ettie: a life of Ettie Rout. Auckland: Penguin, 1992:207-12.

57 Davenport-Hines R. Sex, death and punishment. Attitudes to sex and sexuality in Britain since the Renaissance. London: Collins, 1990:51-4

58 Roddy RE, Zekeng L, Ryan KA, et al. A controlled trial of nonoxynol-9 film to reduce male-to-female transmission of sexually transmitted diseases. N Engl F Med 1998;339:50410

$59 \mathrm{Ku} \mathrm{L}$, Sonenstein FL, Pleck JL. The dynamics of young men's condom use during and across relationships. Family Planning Perspectives 1994;26:246-51.

60 Nutbeam D, Blakely V. The concept of health promotion and AIDS prevention. A comprehensive and integrated basis for action in the 1990s. Health Promotion Int basis for action

61 Moss AR, Osmond D, Bachetti P, et al. Risk factors for AIDS and HIV seropositivity in homosexual men. Am $f$ Epidemiol 1987;125:1035-47.

62 Stone KM, Timyan J, Thomas EL. Barrier methods for the prevention of sexually transmitted diseases. In: Holmes $\mathrm{KK}$, Sparling $\mathrm{PF}, \mathrm{Mår}$ dh $\mathrm{P}-\mathrm{A}$, et al, eds. Sexually transmitted diseases. 3rd ed. New York: McGraw-Hill, 1998:1307-21.

63 Psychoyos A, Creatsas G, Hassan E, et al. Spermicidal and antiviral properties of cholic acid: contraceptive efficacy of the new vaginal sponge (Protectaid7) containing sodium cholate. Hum Reprod 1993;8:866-9.

64 Bourinbaiar AS, Lee-Huang S. Comparative in vitro study of contraceptive agents with anti-HIV activity: gramicidin nonoxynol-9 and gossypol. Contraception 1994;49:131-7.

65 Edwards WM. A study of progonasyl using prostitutes in Nevada's legal houses of prostitution. $\mathscr{f}$ Reprod Med 1973;11:81.

66 Robertson DHH, McMillan A, Young H. Clinical practice in sexually transmissible diseases. Tunbridge Wells: Pitman Medical, 1980:19.

67 Rosenberg MJ, Davidson AJ, Chen JH, et al. Barrier contraceptives and sexually transmitted diseases in women: a comparison of female dependant methods and condoms. Am ₹ Public Health 1992;82:669-74.

68 Hooker E. Male homosexual life styles and venereal disease. In: Proceedings of the World Forum on Syphilis and Treponematoses Atlanta, GA: US Department of Health Treponematoses. Atlanta, GA: US D

69 Lorian V. AIDS, anal sex, and heterosexuals (letter). Lancet 1988;i:1111.

70 Gresenguet G, Kreiss JK, Chapko MK, et al. HIV infection and vaginal douching in Central Africa. AIDS 1997;11: 101-6.

71 Schachter J, Chow JM. Vaginal douching as it relates to reproductive health complications. Curr Opin Infect Dis 1993;6:27-30.

72 Siraprapasiri T, Thanprasertsuk S, Rodklay A, et al. Risk factors for HIV among prostitutes in Chiangmai, Thailand. AIDS 1991;5:579-82.

73 Gibney L, Choudhury P, Khawaja Z, et al. Behavioural risk factors for HIV/AIDS in a low-HIV prevalence Muslim factors for HIV/AIDS in a low-HIV prevalence Muslim

74 Hooper RR, Reynolds GH, Jones OG, et al. Cohort study of venereal disease. I: the risk of gonorrhoea transmission from infected women to men. Am F Epidemiol 1978;108: 136-44.

75 Lewis M. Thorns on the rose: the history of sexually transmitted diseases in Australia in international perspective. Canberra: Australian Government Publishing Service, 1998:211-25.

76 Anonymous. The prophylaxis of venereal disease (letter). Lancet 1918;ii:471.

77 Harrison WO, Hooper RR, Weisner PJ, et al. A trial of minocycline given after exposure to prevent gonorrhea. $N$ Engl F Med 1979;300:1074-8.

78 Khamboonruang C, Beyrer C, Natpratan C, et al. Human immunodeficiency virus infection and self-treatment for sexually transmitted diseases among northern Thai men. Sex Transm Dis 1996;23:264-9. 
79 Barnett B. STD protection after intercourse. Network 1996; 16:20-3

80 Lupton D, McCarthy S, Chapman S. 'Doing the right thing': the symbolic meanings and experiences of having an HIV antibody test. Soc Sci Med 1995;41:173-80.

81 Chitwarakorn A, Sittitrai W, Brown T, et al. Thailand (country chapter). In: Brown T, Chan R, Mugrditchian D, Mulhall B, Plummer D, Sarda R, Sittitrai W, eds. Sexually transmitted diseases in Asia and the Pacific. Armidale (Australia): Venereology Publishing, 1998:305-38.
82 Danziger R. The social impact of HIV testing: a comparative analysis of Britain and Sweden. Soc Sci Med 1999;48:293 300

83 Nuwaha F, Faxelid E, Neema S, et al. Lay people's perceptions of sexually transmitted infections in Uganda. Int $\mathcal{F}$ STD AIDS 1999;10:709-17.

84 Hirschfeld M. The sexual history of the world war. New York: Cadillac Publishing, 1946:132-3.

85 Wysocki DK. Let your fingers do the talking: sex on an adult chat-line. Sexualities 1998;1:425-52. 